\title{
Fast quantification of bovine milk proteins employing external cavity-quantum cascade laser spectroscopy
}

\author{
Andreas Schwaighofer, ${ }^{\mathrm{a}, 1}$, Julia Kuligowskib, ${ }^{\mathrm{b}, 1}$, Guillermo Quintás ${ }^{\mathrm{c}, \mathrm{d}}$, Helmut K. Mayer ${ }^{\mathrm{e}}$, \\ and Bernhard Lendla, ${ }^{\mathrm{a}}$

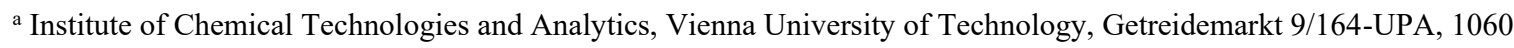 \\ Vienna, Austria

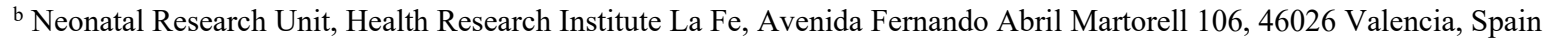 \\ ${ }^{\mathrm{c}}$ Human \& Environmental Health \& Safety (HEHS), Leitat Technological Center, Avenida Fernando Abril Martorell 106, \\ 46026 Valencia, Spain \\ d Unidad Analítica, Health Research Institute La Fe, Avenida Fernando Abril Martorell 106, 46026 Valencia, Spain \\ ${ }^{\mathrm{e}}$ Department of Food Science and Technology, Food Chemistry Laboratory, BOKU - University of Natural Resources and \\ Life Sciences, Muthgasse 11, 1190 Vienna, Austria
}

${ }^{1}$ both authors contributed equally

\begin{abstract}
Analysis of proteins in bovine milk is usually tackled by time-consuming analytical approaches involving wet-chemical, multi-step sample clean-up procedures. The use of external cavity-quantum cascade laser (EC-QCL) based IR spectroscopy was evaluated as an alternative screening tool for direct and simultaneous quantification of individual proteins (i.e. casein and $\beta$-lactoglobulin) and total protein content in commercial bovine milk samples. Mid-IR spectra of protein standard mixtures were used for building partial least squares (PLS) regression models. A sample set comprising different milk types (pasteurized; differently processed extended shelf life, ESL; ultra-high temperature, UHT) was analysed and results were compared to reference methods. Concentration values of the QCL-IR spectroscopy approach obtained within several minutes are in good agreement with reference methods involving multiple sample preparation steps. The potential application as a fast screening method for estimating the heat load applied to liquid milk is demonstrated.
\end{abstract}

Keywords: External cavity-quantum cascade laser (EC-QCL), total protein, casein, $\beta$-lactoglobulin, bovine milk analysis, chemometrics

(C) 2019. This is the peer reviewed version of the following article: J. Kuligowski, A. Schwaighofer, J. Kuligowski, G. Quintás, H.K. Mayer, B. Lendl, Fast quantification of bovine milk proteins employing external cavity-quantum cascade laser spectroscopy, Food Chem. 252 (2018) 22-27, which has been published in final form at https://doi.org/10.1016/j.foodchem.2018.01.082. This manuscript version is made available under the CC-BY-NC-ND 4.0 license http://creativecommons.org/licenses/by-nc$\underline{\mathrm{nd} / 4.0 /}$ 


\section{Introduction}

Milk is considered one of the most nutritionally complete foods available with a recorded production volume of $700 \times 10^{6}$ tonnes per year, of which about $84 \%$ is bovine (O'Mahony \& Fox, 2014). It is mainly composed of water, lipids, lactose and proteins, and their relative amounts vary widely among species, e.g., the percentage range of proteins goes from 10 to $200 \mathrm{~g} \mathrm{~L}^{-1}$, with a total protein content of $\sim 32 \mathrm{~g} \mathrm{~L}^{-1}$ for bovine milk. Casein (Cas) proteins represent approximately $80 \%$ of the total protein content in bovine milk, and the remaining $20 \%$ belong to whey proteins (Haug, Høstmark, \& Harstad, 2007). The two most prominent and abundant proteins in milk are casein and $\beta$ lactoglobulin ( $\beta-\mathrm{LG}$ ) with concentrations of $\sim 25 \mathrm{~g} \mathrm{~L}^{-1}$ (entire casein fraction) and $\sim 3.8 \mathrm{~g} \mathrm{~L}^{-1}$ (Fox, Uniacke-Lowe, McSweeney, \& O’Mahony, 2015).

Milk and dairy product consumption is recommended by most nutritional societies because they provide a combination of key nutrients such as calcium, potassium and protein (Rozenberg et al., 2016). The three most widespread commercially available milk types are pasteurized milk, extended shelf life (ESL) milk as well as ultra-high-temperature (UHT) milk, that undergo different thermal treatment resulting in varying shelf life and are accompanied by flavour and nutrient degradation (Hougaard, Vestergaard, Varming, Bredie, \& Ipsen, 2011). Pasteurized milk receives the mildest thermal treatment (e.g. $15 \mathrm{~s}$ at $72{ }^{\circ} \mathrm{C}$ ) and is storable for 10 days in cold storage. In contrast, UHT milk is storable at ambient temperature for 6 months after being subjected to heating at a temperature of at least $135^{\circ} \mathrm{C}$ for no less than $1 \mathrm{~s}$ (Rysstad \& Kolstad, 2006), which may introduce a perceived "cooked" taste. ESL milk has gained widespread acceptance recently as it provides longer storage time than pasteurized milk (21-24 days under chilled conditions), while maintaining fresh quality and noncooked flavour (Schmidt, Kaufmann, Kulozik, Scherer, \& Wenning, 2012). Currently employed methods to produce ESL milk are microfiltration, direct heat treatment (HTST - high temperature short time) by injection or infusion (e.g. $127^{\circ} \mathrm{C}$ for $2-3 \mathrm{~s}$ ), or in many cases also indirect heat treatment (e.g. $125^{\circ} \mathrm{C}$ for $2 \mathrm{~s}$ ) (Rysstad et al., 2006).

Intensive heat processing is known to induce organoleptic and nutritional changes. Analysis of specific species that are affected by heat treatment (formation or degradation) allows quantitative assessment of the heat load impact without knowledge of the preceding thermal history (Claeys, Smout, Van Loey, \& Hendrickx, 2004). Denaturation of $\beta$-LG begins at approx. $60{ }^{\circ} \mathrm{C}$, thus this protein has been proposed as indicator for low-heat treatment and the remaining concentration of undenatured acid-soluble $\beta$-LG can be employed to distinguish between pasteurized and UHT milk (Boitz, Fiechter, Seifried, \& Mayer, 2015). The International Dairy Federation (IDF) proposed a minimum $\beta$-LG content of $2.6 \mathrm{~g} \mathrm{~L}^{-1}$ for pasteurized milk, of $2.0 \mathrm{~g} \mathrm{~L}^{-1}$ for high-pasteurized milk, and of $0.05 \mathrm{~g} \mathrm{~L}^{-1}$ for UHT milk (Mayer, Raba, Meier, \& Schmid, 2010). For liquid ESL milk, threshold limits currently are not mandatory, in contrast to pasteurized/UHT milk.

The reference analytical technique for determination of the total protein content in milk is still the historic Kjeldahl method for determination of organic nitrogen in food and beverages, in spite of being a rather labour-intensive wet-chemical routine with low throughput (Ribadeau-Dumas \& Grappin, 1989). For quantification of individual milk proteins including Cas and $\beta-L G$, several methods based on chromatographic (Bordin, Cordeiro Raposo, de la Calle, \& Rodriguez, 2001; Mayer et al., 2010; Strange, Malin, Van Hekken, \& Basch, 1992) and electrophoretic (Strange et al., 1992) approaches were reported, that still involve time-consuming, wet-chemical sample preparation steps. Application of mid-infrared (IR) spectroscopy has been adopted for rapid and non-destructive analysis of the quality and composition of dairy products due to their high-throughput capacity, low cost and simplicity (Aernouts, Polshin, Saeys, \& Lammertyn, 2011; Etzion, Linker, Cogan, \& Shmulevich, 
2004; Mazurek, Szostak, Czaja, \& Zachwieja, 2015). Moreover, a technique based on IR spectroscopy has been accepted by the Association of Official Analytical Chemists (AOAC International) for analysis of liquid milk, that led to the development of several commercially available FTIR milk analysers for determination of total protein and casein content, among other parameters (Kaylegian, Lynch, Houghton, Fleming, \& Barbano, 2006).

Mid-IR spectroscopy detects the fundamental vibrations of covalent bonds in molecules and provides qualitative and quantitative information of the constituents that absorb mid-IR radiation. For structure analysis of proteins, the amide I (1600-1700 $\left.\mathrm{cm}^{-1}\right)$ and amide II (1500-1600 $\left.\mathrm{cm}^{-1}\right)$ bands are most commonly used. The amide I band has been shown to be particularly sensitive to the secondary protein structure (Barth, 2007). IR spectroscopy has been intensively employed for analysis of different parameters in milk (Gondim, Junqueira, de Souza, Ruisanchez, \& Callao, 2017; Jaiswal, Jha, Kaur, \& Borah, 2017; Justino, Rocha-Santos, \& Duarte, 2010), and in particular for protein analysis in milk. For quantitative analysis of total protein content, most commonly the amide II band is employed at a path length of $\sim 50 \mu \mathrm{m}$ for transmission measurements, usually in combination with multivariate calibration (Aernouts et al., 2011; Etzion et al., 2004; Luinge, Hop, Lutz, Vanhemert, \& Dejong, 1993; Moore, DeVries, Lipp, Griffiths, \& Abernethy, 2010). Discrimination between proteins based on secondary structure is preferentially performed by evaluating the amide I band. However, the development of FTIR-based applications in the $1600-1700 \mathrm{~cm}^{-1}$ spectral region is troublesome due to the low emission powers of thermal light sources in conventional FTIR spectrometers and the strong absorbance of $\mathrm{H}_{2} \mathrm{O}$ centred at $1645 \mathrm{~cm}^{-1}$. Consequently, suitable path lengths are restricted to $<10 \mu \mathrm{m}$, to prevent total IR absorption in this region, which compromises sensitivity levels necessary for the study of biologically relevant concentrations and considerably impair the ruggedness of the application. As an alternative to conventional FTIR spectroscopy, custom-built setups based on quantum cascade lasers have gained numerous applications in mid-IR spectroscopy (Schwaighofer, Brandstetter, \& Lendl, 2017). It has been shown that by employing an external cavity-quantum cascade laser (EC-QCL) light source with significantly higher emission intensities, the optical path can be increased to $38 \mu \mathrm{m}$ for mid-IR measurements in aqueous solutions covering the amide I spectral region (Alcaráz et al., 2015). EC-QCL-based IR transmission measurements have been successfully accomplished for the analysis of protein secondary structure (Alcaráz, Schwaighofer, Goicoechea, \& Lendl, 2016; Schwaighofer, Alcaraz, Araman, Goicoechea, \& Lendl, 2016). Most recently, the feasibility of protein discrimination and quantification in commercial bovine milk samples have been demonstrated by QCL-IR spectroscopy and evaluation of the amide I band using partial least squares (PLS) modelling (Kuligowski et al., 2017).

This work aims at validating the fast and direct quantification of individual protein (i.e. casein and $\beta$-LG) and total bovine milk protein content employing an EC-QCL setup by means of the analysis of a sample set comprising different milk types and comparison to a reference method. Commercial bovine milk has been chosen as the subject of our research, as it poses an important food with widespread consumption and high nutritional value. Because various heat treatments change the content of certain key nutrients (e.g. vitamins, amino acids), rapid differentiation between differently processed milk types is of crucial importance for quality control of commercial drinking milk. The potential application of the presented method as a fast screening method for estimating the heat load applied to commercial liquid milk samples is demonstrated. 


\section{Materials and Methods}

\subsection{Standards and reagents}

Ethanol (96\% v/v, EtOH), aqueous sodium hydroxide $(\mathrm{NaOH})$ solution $(50 \%)$, hydrochloric acid $37 \%$ (HCl) ACS reagent, $\alpha$-lactose monohydrate $(\geq 99 \%, \alpha$-Lac), lyophilized powder of $\beta$-LG $(\geq 90 \%)$ and Cas sodium salt, both from bovine milk, were obtained from Sigma-Aldrich (Steinheim, Germany). Sodium phosphate monobasic dihydrate p.a. $\left(\mathrm{NaH}_{2} \mathrm{PO}_{4} \cdot 2 \mathrm{H}_{2} \mathrm{O}\right)$ was purchased from Fluka (Buchs, Switzerland). A Merck Millipore (Darmstadt, Germany) Milli-Q water purification system was used for generating ultrapure water. Solvents used for chromatographic analysis were of HPLCgrade. Sixteen homogenized, commercial bovine milk samples (four different brands of pasteurized, ESL filtered, ESL HTST and UHT type each) were obtained from local grocery stores.

\subsection{Preparation of solutions}

Individual stock solutions of Cas and $\beta-\mathrm{LG}$ at concentrations of 40 and $30 \mathrm{~g} \mathrm{~L}^{-1}$, respectively, were prepared by direct weighing of the corresponding amount of lyophilized protein powder in a $5 \mathrm{~mL}$ volumetric flask and dissolving with $45 \mathrm{mmol} \mathrm{L}^{-1}$ phosphate buffer at $\mathrm{pH}$ 6.6. Ten standard solutions containing protein mixtures were prepared by dilution of the corresponding stock solutions in $45 \mathrm{mmol} \mathrm{L}^{-1}$ phosphate buffer at $\mathrm{pH} 6.6$, reaching concentrations ranging between 0 and $30 \mathrm{~g} \mathrm{~L}^{-1}$ for Cas, and 0 and $15 \mathrm{~g} \mathrm{~L}^{-1}$ for $\beta$-LG. Total protein concentrations resulted from the sum of individual protein concentrations and ranged between 19 and $36 \mathrm{~g} \mathrm{~L}^{-1}$ (Kuligowski et al., 2017).

An $\alpha$-Lac solution was prepared at a concentration of $48 \mathrm{~g} \mathrm{~L}^{-1}$ by weighing and dissolution of the appropriate amount of $\alpha$-Lac monohydrate in $45 \mathrm{mmol} \mathrm{L}^{-1}$ phosphate buffer at $\mathrm{pH}$ 6.6.

\subsection{EC-QCL setup}

A detailed description of the custom-made EC-QCL setup can be found elsewhere (Alcaráz et al., 2015). Briefly, the setup is equipped with an EC-QCL from Daylight Solutions Inc. (San Diego, USA) with a spectral tuning range from 1729.30 to $1565.06 \mathrm{~cm}^{-1}$, a temperature-controlled $38 \mu \mathrm{m}$ path length flow cell with $\mathrm{CaF}_{2}$ windows and a thermoelectrically cooled $\left(-60^{\circ} \mathrm{C}\right)$ mercury-cadmiumtelluride detector (MCT-7-TE3; $\mathrm{D}^{*}=4 \times 10^{9} \mathrm{~cm} \mathrm{~Hz}^{0.5} \mathrm{~W}^{-1}$ at $9.2 \mu \mathrm{m}$ ) from Infrared Associates Inc. (Stuart, FL, USA), see Fig. 1. The laser was thermoelectrically cooled for maintaining a head temperature of $18{ }^{\circ} \mathrm{C}$ and operated in pulsed mode at a repetition rate of $100 \mathrm{kHz}$ and a pulse width of $500 \mathrm{~ns}$. A gold plated off-axis parabolic mirror with a focal length of $43 \mathrm{~mm}$ was used to focus the

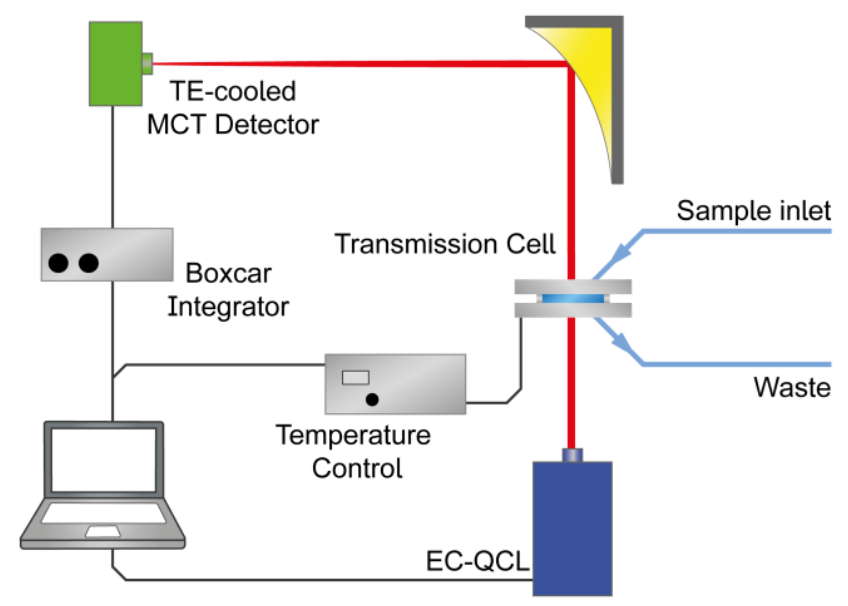

Fig. 1. Schematic of the experimental EC-QCL based IR transmission setup. For measurements of milk, a path length of $38 \mu \mathrm{m}$ was used. 
mid-IR light on the detector. The measured signal was processed by a two-channel boxcar integrator and digitized by a NI DAQ 9239 24-bit analogue-to-digital converter from National Instruments Corp. (Austin, USA) at a sampling rate of $16 \mathrm{kHz}$. The setup was placed in a housing of polyethylene foil, which was constantly flushed with dry air in order to reduce the influence of water vapour. An inhouse written graphical user interface with server-client program structure developed in LabView (version 11.0, National Instruments Corp., Austin, USA) was used for controlling the entire setup.

Single beam spectra comprising 24000 data points were recorded during the EC-QCL tuning time of $1.5 \mathrm{~s}$, and a total of 100 scans were accumulated for background and sample measurements resulting in a total acquisition time of $\sim 8.3 \mathrm{~min}$. For IR measurements of bovine milk, deionized water was used as a background, whereas $45 \mathrm{mmol} \mathrm{L}^{-1}$ phosphate buffer $\mathrm{pH} 6.6$ was used as background for protein standard solutions. After each measurement, the flow-cell was cleaned with $2 \mathrm{~mL}$ of EtOH, diluted $\mathrm{NaOH}, \mathrm{HCl}$ and distilled water. All solutions were manually injected into the flow cell employing a $1 \mathrm{~mL}$ disposable syringe.

\subsection{Data processing}

Data processing was performed in MATLAB 2013b (Mathworks Inc., Nattick, USA) using builtin and in-house written routines as well as the PLS Toolbox 8.0 from Eigenvector Research Inc. (Wenatchee, USA). The performed pre-processing routine for EC-QCL raw data aims at correcting the spectral mismatch of successive scans which is caused by irregular shifts in the fine structure of the EC-QCL light source due to mechanical imperfections and triggering issues and is based on the correlation optimized warping algorithm (Alcaráz et al., 2015).

For bovine milk spectra, prior to the determination of proteins, the subtraction of the spectral contribution of the milk matrix from the overall IR signal was necessary. Accordingly, the multivariate science-based calibration (SBC) method (Marbach, 2010) was used to achieve a reliable estimation of matrix proportion in milk sample spectra reflected in variations in the absorbance intensity of the $\mathrm{H}_{2} \mathrm{O}$ band at $1645 \mathrm{~cm}^{-1}$ due to the displacement of water caused by milk matrix compounds relative to the $\mathrm{H}_{2} \mathrm{O}$ background spectrum. To this end, an $\alpha$-Lac spectrum was used as response spectrum of the matrix signal and a set of 10 synthetic tertiary protein standard mixtures with a constant concentration of the matrix component of zero was used as noise matrix for the calculation of the spectral noise. The background correction procedure has been explained in detail elsewhere (Kuligowski et al., 2017). A univariate receiver operating characteristic (ROC) curve employing $\beta$-LG concentrations and two heat-load classes (low and high) was computed employing MetaboAnalyst 3.0 (Xia, Sinelnikov, Han, \& Wishart, 2015).

\subsection{Determination of nitrogen content using Kjeldahl method}

Total nitrogen (TN) was determined by the Kjeldahl method according to the corresponding IDF/ISO standard (IDF/ISO, 2001a), non-casein N (NCN) according to IDF/ISO (IDF/ISO, 2004), and non-protein N (NPN) according to IDF/ISO (IDF/ISO, 2001b). Whey protein N was calculated from the difference between $\mathrm{NCN}$ and NPN, and casein $\mathrm{N}$ from TN and NCN, respectively. Protein equivalents were calculated from nitrogen data using the factor 6.38 .

\subsection{Reversed Phase - High Performance Liquid Chromatography (RP-HPLC) analysis of acid- soluble $\beta$ - $L G$}

Sample preparation for the determination of $\beta$-LG as well as RP-HPLC analysis were carried out according to the corresponding IDF/ISO standard (IDF/ISO, 2005) and as described recently (Boitz \& Mayer, 2017; Mayer et al., 2010). Briefly, caseins and denatured whey proteins were precipitated at $\mathrm{pH} 4.6$ by dropwise addition of $\mathrm{HCl}\left(2 \mathrm{~mol} \mathrm{~L}^{-1}\right)$. Acid whey containing the acid-soluble whey proteins 
was separated by centrifugation and diluted $(1: 10$, or $1: 5$ in the case of UHT milk) with sodium phosphate buffer solution ( $0.1 \mathrm{~mol} \mathrm{~L}^{-1}, \mathrm{pH}$ 6.7). Samples were filtered through $0.20 \mu \mathrm{m}$ Minisart RC 4 filters (Sartorius, Goettingen, Germany).

RP-HPLC was performed on a Waters chromatography system using a model 600E multisolvent delivery system, a Rheodyne $7725 \mathrm{i}$ injector, guard column (Sentry Guard, Symmetry ${ }^{\mathrm{TM}} \mathrm{C}_{18}, 3.5 \mu \mathrm{m}$, $2.1 \times 10 \mathrm{~mm}$ ) and a Symmetry ${ }^{\mathrm{TM}} 300 \mathrm{C}_{18}$ column $(3.5 \mu \mathrm{m}, 2.1 \times 150 \mathrm{~mm})$ (Waters Corporation, Milford, MA, USA). Column eluates were monitored at $205 \mathrm{~nm}$ using a Waters $2489 \mathrm{UV} / \mathrm{VIS}$ Detector interfaced with a PC running Waters Millennium chromatography software for data acquisition and management.

Gradient separation was carried out within $18 \mathrm{~min}$, followed by column equilibration leading to sample injection intervals of $35 \mathrm{~min}$ (Mayer et al., 2010). Solvent A consisted of $0.1 \%$ trifluoroacetic acid (TFA) in ultrapure water, solvent B of $0.1 \%$ TFA in acetonitrile. Solvents for HPLC analysis were freshly prepared weekly and vacuum filtered (Whatman ${ }^{\mathrm{TM}}$, ME24ST Membrane Filters White, $0.2 \mu \mathrm{m}$, diameter $47 \mathrm{~mm}$ ) before use. Gradient elution was carried out by increasing solvent B linearly from $36 \%$ to $50 \%$ over $14 \mathrm{~min}$, followed by increasing to $100 \% \mathrm{~B}$ within $0.5 \mathrm{~min}$, and finally holding at $100 \% \mathrm{~B}$ for $3.5 \mathrm{~min}$. Separation was performed at a column temperature of $40{ }^{\circ} \mathrm{C}$ with a flow rate of $0.35 \mathrm{~mL} \mathrm{~min}^{-1}$ and the injection volume was set to $10 \mu \mathrm{L}$ (Mayer et al., 2010).

\section{Results and discussion}

\subsection{IR spectra recorded with the EC-QCL setup}

Recorded IR spectra of individual Cas and $\beta$-LG standard solutions as well as a bovine milk sample after SBC based background correction are shown in Fig. 2. It should be emphasized that the position and shape of the amide I band change depending on the secondary structure of the protein. The irregular and extended $\alpha$-helical secondary structure of Cas causes a broad IR absorbance band with a maximum at $1650 \mathrm{~cm}^{-1}$ (Farrell, Wickham, Unruh, Qi, \& Hoagland, 2001), whereas the $\beta$-LG spectrum shows a band shape characteristic for $\beta$-sheet rich proteins with a maximum at $1632 \mathrm{~cm}^{-1}$ and a shoulder located at approximately $1660 \mathrm{~cm}^{-1}$ (Bhattacharjee, Saha, Biswas, Kundu, Ghosh, \& Das, 2005). The shape of the bovine milk spectrum (see Fig. 2) reflects a predominant proportion of Cas.

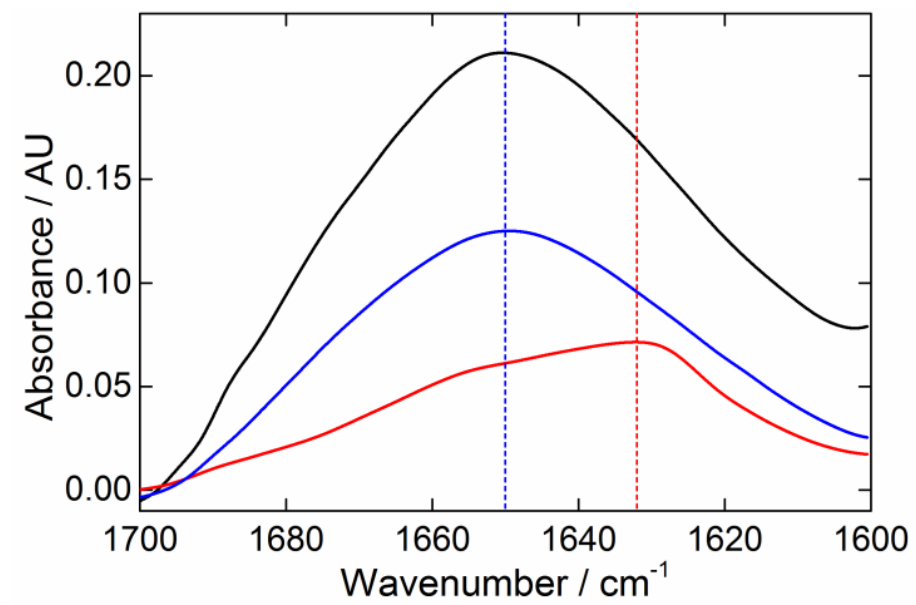

Fig. 2. Mid-IR absorbance spectra of $20 \mathrm{~g} \mathrm{~L}^{-1}$ of Cas (blue), $10 \mathrm{~g} \mathrm{~L}^{-1}$ of $\beta$-LG (red) and bovine milk after background correction (black) using a phosphate buffer spectrum as background; dashed lines located at $1650 \mathrm{~cm}^{-1}$ (blue) and $1632 \mathrm{~cm}^{-1}$ (red) reflect the positions of the absorption band maxima in mid-IR spectra of Cas and $\beta-\mathrm{LG}$, respectively. 
Nevertheless, minor $\beta$-LG contents lead to a shoulder observed in the region around $1632 \mathrm{~cm}^{-1}$. Fig. 2 clearly illustrates that in spite of the spectral differences observed, there is a strong overlap between both typical protein signals in the studied IR region, indicating the need for a multivariate calibration approach for protein quantification in this complex multicomponent system.

\subsection{Quantification of bovine milk proteins}

Application of alkaline and sodium dodecyl sulfate - polyacrylamide gel electrophoresis (SDSPAGE) had confirmed the presence of the investigated proteins in the sampled milk types (Boitz et al., 2017; Mayer, Raba, Meier, \& Schmid, 2009). To tackle direct protein quantification by EC-QCL based IR spectroscopy in bovine milk samples, PLS regression models were built based on synthetic protein standard mixtures. PLS calibration parameters and internal figures of merit for the determination of the most abundant proteins found in bovine milk (i.e. Cas and $\beta-\mathrm{LG}$ ), as well as for the total protein content are displayed in Table 1. All three models involved the calculation of derivative spectra as well as mean centering prior to PLS model calculation. For PLS regression models, between 1 and 5 latent variables (LVs) were employed. Coefficients of determination $\left(\mathrm{R}^{2}\right)$ of calibration and leave-one-out cross validation are a measure of the goodness of fit for the calibration data set and were $\geq 0.96$ and 0.93 , respectively. Root-mean square error of calibration (RMSEC) and cross-validation (RMSECV) ranged between 0.4 and $1.0 \mathrm{~g} \mathrm{~L}^{-1}$ as well as 0.5 and $1.4 \mathrm{~g} \mathrm{~L}^{-1}$, respectively, while the $\mathrm{CV}$ bias as a measure of accuracy ranged between -0.008 and $0.06 \mathrm{~g} \mathrm{~L}^{-1}$. In general, models for the determination of Cas and total protein content showed better figures of merit than for the determination of $\beta-L G$ as expected due to the lower abundance of the latter.

Table 1. PLS calibration parameters and internal figures of merit.

\begin{tabular}{|c|c|c|c|}
\hline Parameter & $\begin{array}{c}\text { Cas } \\
\left(0-30 \mathrm{~g} \mathrm{~L}^{-1}\right)\end{array}$ & $\begin{array}{c}\beta-L G \\
\left(0-15 \mathrm{~g} \mathrm{~L}^{-1}\right)\end{array}$ & $\begin{array}{c}\text { Total } \\
\left(19-36 \mathrm{~g} \mathrm{~L}^{-1}\right)\end{array}$ \\
\hline Preprocessing & $2^{\text {nd }}$ Der. $+M C$ & $\mathrm{BLC}+2^{\text {nd }}$ Der. $+\mathrm{MC}$ & $1^{\text {st }}$ Der. $+\mathrm{MC}$ \\
\hline LVs & 5 & 1 & 2 \\
\hline $\mathrm{R}^{2}$ cal & 0.995 & 0.96 & 0.996 \\
\hline $\mathrm{R}^{2} \mathrm{CV}$ & 0.990 & 0.93 & 0.994 \\
\hline RMSEC $\left[\mathrm{g} \mathrm{L}^{-1}\right]$ & 0.4 & 1.0 & 0.4 \\
\hline $\operatorname{RMSECV}\left[\mathrm{g} \mathrm{L}^{-1}\right]$ & 1.4 & 1.3 & 0.5 \\
\hline CV bias $\left[\mathrm{g} \mathrm{L}^{-1}\right]$ & 0.06 & 0.06 & -0.008 \\
\hline
\end{tabular}

Note: $\mathrm{MC}=$ mean centering; $1^{\text {st }}$ and $2^{\text {nd }}$ Der. $=$ first and second derivative calculated using the Savitzky-Golay filter (order: 3, window: 15 points); BLC = baseline correction (linear fit between $\left.1601-1700 \mathrm{~cm}^{-1}\right) ; \mathrm{LV}=$ latent variable; $\mathrm{R}^{2}=$ coefficient of determination; cal = calibration; $\mathrm{CV}=$ cross validation; $\mathrm{RMSEC}=$ root mean square error of calibration given in $\mathrm{g} \mathrm{L}^{-}$ 1; RMSECV $=$ root mean square error of cross validation given in $\mathrm{g} \mathrm{L}^{-1}$; $\mathrm{RMSE}=$ $\sqrt{\sum_{1}^{\mathrm{I}}\left(c_{\text {nom }}-c_{\text {pred }}\right)^{2}}$.

The described PLS regression models were employed for the direct determination of proteins in bovine milk samples obtained from local retail stores and the found concentrations were compared to those determined employing reference procedures as described in the methods section, see Table 2. In this study, four different milk types were distinguished, including (i) pasteurized, (ii) ESL filtered, (iii) ESL HTST and (iv) UHT type milk. For total protein, concentrations determined employing QCL-IR 
spectroscopy and chemometrics provided concentrations with median values varying between 28.8 and $38 \mathrm{~g} \mathrm{~L}^{-1}$ in different milk types. The accuracy and precision of the found concentrations were assessed by the obtained recoveries with respect to the reference method with median values ranging between 91 and $109 \%$ and IQRs of 0.8 to $5 \%$. Two samples of the ESL HTST type were proteinenriched milk products. The higher total protein content was correctly reflected by the QCL-IR based method. Similarly, determined casein contents showed median values between 23.6 and $30 \mathrm{~g} \mathrm{~L}^{-1}$ for the studied milk samples. Accuracy and precision with respect to the reference method were reflected in median recoveries ranging between 91 and $109 \%$, and IQRs of 4 to $10 \%$. From the heat treatment, no denaturation of casein is expected due to their irregular and flexible secondary structure (O'Mahony et al., 2014). Heat-induced interaction of caseins with whey proteins and aggregation does not alter their secondary structure and thus does not impair detection by IR spectroscopy. In case of $\beta$-LG, for milk samples which were not subjected to high temperature treatments (i.e. pasteurized and ESL filtered milk), results from the EC-QCL setup provided medians of 3.7 and $3.5 \mathrm{~g} \mathrm{~L}^{-1}$, respectively. In comparison to the reference determinations, also here reasonable recoveries of 108 and $123 \%$ with IQRs of 101 and $124 \%$, respectively, were found. Conversely, when high temperatures were applied during pasteurization, only 1.8 to $2.2 \mathrm{~g} \mathrm{~L}^{-1}$ of $\beta$-LG were determined and considerably higher recoveries were achieved, when compared to acid-soluble $\beta$-LG determined by the HPLC method (i.e. 1224 to $1321 \%$ ).

For the milk samples experiencing high temperature treatment, it is disputable if comparison of the $\beta$ LG concentrations obtained by QCL-IR spectroscopy are directly comparable with acid-soluble $\beta$-LG determined by the HPLC method, due to the different kind of information that is obtained by the respective analytical procedures. The nature of acid-soluble $\beta$-LG fulfils the definition of a methoddefined parameter (Simonet, Lendl, \& Valcarcel, 2006), thus the obtained values are inherently not reproducible by different methods. Throughout exposure to high temperatures, the proteins in milk undergo several processes. There is denaturation of whey proteins at elevated temperatures which is a known and well researched issue (Boitz et al., 2017; Mayer et al., 2010; O'Mahony et al., 2014). Reversible changes of $\beta$-LG secondary structure occurring above approx. $60{ }^{\circ} \mathrm{C}$ become irreversible when milk is subjected to temperatures $>70{ }^{\circ} \mathrm{C}$ for prolonged time (Wijayanti, Bansal, \& Deeth, 2014). Further, there are intermolecular interactions between cysteines of $\beta$-LG with disulphides of casein leading to aggregation. This protein-protein interaction may not necessarily be linked to denaturation of the $\beta$-LG secondary structure. For determination of acid-soluble $\beta$-LG, the caseins along with bound $\beta$-LG are precipitated and separated under acidic conditions, while the supernatant liquid is used for HPLC analysis. Consequently, values obtained by this method inherently do not reflect the whole amount of $\beta$-LG present in milk. For QCL-IR measurements, the milk sample is used in its entirety, without sample preparation. This method detects native $\beta$-LG (i.e. $\beta$-sheet) secondary structure present in milk, regardless of being acid-soluble or bound to casein. Therefore, the found $\beta$ LG concentrations by QCL-IR spectroscopy are higher than values determined by the HPLC method. Nevertheless, the obtained $\beta$-LG concentrations by QCL-IR spectroscopy allow discrimination between milk subjected to high- and low-heat load (as described in section 3.3) even though being not directly comparable to the values obtained for acid-soluble $\beta$-LG.

By QCL-IR spectroscopy, in general lower precisions were obtained as compared to the reference procedures reflected in the number of significant digits of the calculated standard deviations, as well as the obtained inter-quartile ranges (IQRs). However, this drawback may be compensated by the enormous saving in terms of sample preparation and analysis time. Manual sample preparation is completely avoided, and IR spectra used for the simultaneous determination of all three measurement 
Table 2. Protein concentration values of four different milk types obtained by EC-QCL spectroscopy and reference methods.

\begin{tabular}{|c|c|c|c|c|c|c|c|c|c|c|c|c|}
\hline \multirow[t]{3}{*}{ Milk Type } & \multicolumn{12}{|c|}{ Cas } \\
\hline & \multicolumn{4}{|c|}{ EC-QCL $\left[\mathrm{g} \mathrm{L}^{-1}\right]$} & \multicolumn{4}{|c|}{ Reference Method $\left[\mathrm{g} \mathrm{L}^{-1}\right.$ ] } & \multicolumn{4}{|c|}{ Recovery [\%] } \\
\hline & Mean $\pm \mathrm{s}$ & Min - max & Median (IQR) & P. $10-$ P. 90 & Mean $\pm \mathrm{s}$ & $\operatorname{Min}-\max$ & Median (IQR) & P. $10-$ P. 90 & Mean $\pm \mathrm{s}$ & $\operatorname{Min}-\max$ & Median (IQR) & P. $10-$ P. 90 \\
\hline Pasteurized & $23.6 \pm 1.1$ & $22.1-25.1$ & $24(2)$ & $22-25$ & $25.9 \pm 0.5$ & $25.4-26.7$ & $25.8(0.4)$ & $25.4-26.7$ & $91 \pm 3$ & $86-96$ & $91(4)$ & $87-94$ \\
\hline ESL filtered & $25 \pm 2$ & $22-27$ & $26(2)$ & $23-27$ & $25.3 \pm 0.4$ & $24.7-25.8$ & $25.4(0.6)$ & $24.7-25.8$ & $100 \pm 7$ & $86-107$ & $102(7)$ & $88-106$ \\
\hline ESL HTST & $30 \pm 3$ & $26-34$ & $30(3)$ & $27-33$ & $29 \pm 2$ & $26-31$ & $28(4)$ & $26-31$ & $105 \pm 5$ & $98-113$ & $107(9)$ & $99-112$ \\
\hline \multirow[t]{4}{*}{ UHT } & $29 \pm 2$ & $26-33$ & $29(2)$ & $26-31$ & $26.5 \pm 0.3$ & $26.1-26.8$ & $26.6(0.3)$ & $26.1-26.8$ & $108 \pm 8$ & $97-124$ & $109(10)$ & $99-116$ \\
\hline & \multicolumn{12}{|c|}{$\beta-\mathbf{L G}$} \\
\hline & \multicolumn{4}{|c|}{ EC-QCL $\left[\mathrm{g} \mathrm{L}^{-1}\right]$} & \multicolumn{4}{|c|}{ Reference Method $\left[\mathrm{g} \mathrm{L}^{-1}\right]$} & \multicolumn{4}{|c|}{ Recovery [\%] } \\
\hline & Mean $\pm \mathrm{s}$ & Min - max & Median (IQR) & P. $10-$ P. 90 & Mean $\pm \mathrm{s}$ & Min $-\max$ & Median (IQR) & P. $10-$ P. 90 & Mean $\pm \mathrm{s}$ & Min $-\max$ & Median (IQR) & P. $10-$ P. 90 \\
\hline Pasteurized & $3.7 \pm 0.6$ & $2.8-4.5$ & $3.8(1.0)$ & $2.9-4.4$ & $3.5 \pm 0.4$ & $2.9-3.8$ & $3.8(0.3)$ & $2.9-3.8$ & $108 \pm 28$ & $76-159$ & $101(36)$ & $79-146$ \\
\hline ESL filtered & $3.5 \pm 0.2$ & $3.0-3.9$ & $3.5(0.3)$ & $3.3-3.7$ & $2.9 \pm 0.5$ & $2.4-3.6$ & $2.8(0.7)$ & $2.4-3.6$ & $123 \pm 25$ & $82-160$ & $124(34)$ & $90-150$ \\
\hline ESL HTST $^{\mathrm{a}}$ & $1.8 \pm 0.7$ & $0.7-2.4$ & $2.1(0.6)$ & $0.8-2.3$ & $0.69 \pm 1.10$ & $0.10-2.45^{\mathrm{a}}$ & $0.1(0.6)$ & $0.1-2.5$ & $1224 \pm 885$ & $76-2200$ & $1372(1441)$ & $84-2120$ \\
\hline \multirow[t]{4}{*}{ UHT } & $2.2 \pm 0.3$ & $1.6-2.7$ & $2.2(0.4)$ & $1.8-2.6$ & $0.17 \pm 0.02$ & $0.14-0.20$ & $0.17(0.02)$ & $0.14-0.20$ & $1321 \pm 245$ & $932-1788$ & $1252(341)$ & $1114-1588$ \\
\hline & \multicolumn{12}{|c|}{$\begin{array}{c}\text { Total Proteins } \\
\end{array}$} \\
\hline & \multicolumn{4}{|c|}{ EC-QCL $\left[\mathrm{g} \mathrm{L}^{-1}\right]$} & \multicolumn{4}{|c|}{ Reference Method $\left[\mathrm{g} \mathrm{L}^{-1}\right]$} & \multicolumn{4}{|c|}{ Recovery [\%] } \\
\hline & Mean $\pm \mathrm{s}$ & Min - max & Median (IQR) & P. $10-$ P. 90 & Mean $\pm s$ & Min $-\max$ & Median (IQR) & P. $10-$ P. 90 & Mean $\pm \mathrm{s}$ & Min $-\max$ & Median (IQR) & P. $10-$ P. 90 \\
\hline Pasteurized $^{\mathrm{b}}$ & $28.9 \pm 0.9$ & $27.8-30.0$ & $28.8(1.5)$ & $27.8-30.0$ & $31.4 \pm 0.5$ & $30.9-32.3$ & $31.3(0.4)$ & $30.9-32.3$ & $92 \pm 2$ & $89-95$ & $91(3)$ & 90-95 \\
\hline $\begin{array}{c}\text { ESL } \\
\text { filtered }^{\mathrm{b}}\end{array}$ & $29.6 \pm 0.5$ & $28.9-30.3$ & $29.7(0.9)$ & $29.0-30.2$ & $30.8 \pm 0.5$ & $30.0-31.3$ & $30.9(0.7)$ & $30.0-31.3$ & $96.2 \pm 0.6$ & $95.3-97.1$ & $96.2(0.8)$ & $95.4-96.8$ \\
\hline ESL HTST $^{c}$ & $38 \pm 3$ & $34-42$ & $38(6)$ & $35-42$ & $35 \pm 3$ & $32-38$ & $34(5)$ & $32-38$ & $110 \pm 2$ & $107-113$ & $109(2)$ & $108-112$ \\
\hline $\mathrm{UHT}^{\mathrm{b}}$ & $31 \pm 2$ & $29-35$ & $31(2)$ & $30-35$ & $32.2 \pm 0.4$ & $31.7-32.6$ & $32.3(0.4)$ & $31.7-32.6$ & $97 \pm 6$ & 93-108 & $94(5)$ & 93-107 \\
\hline
\end{tabular}

Note: All concentrations given in $\mathrm{g} \mathrm{L}^{-1}$; IQR stands for interquartile range; P. 10 and P. 90 stand for percentile 10 and 90 , respectively.

${ }^{a}$ This group contains two protein enriched milk products

botal protein concentrations according to package labelling: $33-34 \mathrm{~g} \mathrm{~L}^{-1}$

ctotal protein concentrations according to package labelling: $34-41 \mathrm{~g} \mathrm{~L}^{-1}$ 
parameters are recorded within minutes of acquisition time. Quantification furthermore relies on the use of an external calibration data set and the lactose spectrum used for background correction, which only were collected once. Background correction of sample milk spectra recorded on different measurement days and subsequent quantification of Cas, $\beta-\mathrm{LG}$ and total protein content can be carried out in a semi-automatized fashion employing a standard PC.

\subsection{Estimation of heat load in commercial milk samples by evaluation of $\beta$-LG concentrations}

The potential of evaluating the $\beta-L G$ concentrations to estimate the experienced heat load of processed milk has been successfully demonstrated (Boitz et al., 2015; Boitz et al., 2017; Mayer et al., 2010). Here, the $\beta$-LG concentration values obtained for different milk types by QCL-IR spectroscopy and chemometrics were employed to classify the milk samples according to the experienced heat load during processing. The constructed ROC curve showed an area under the curve of 1 ( $95 \%$ confidence interval 1-1), and hence highly significant differences were found with a threshold at $2.7 \mathrm{~g} \mathrm{~L}^{-1} \beta$-LG enabling classification of bovine milk samples which received low vs. high heat load. Fig. 3 illustrates the $\beta$-LG levels found for milk samples subjected to pasteurization (pasteurized + ESL filtered) and high temperature treatment steps (ESL HTST + UHT). Remarkably, QCL-IR spectroscopy is capable of distinguishing ESL milk manufactured by different production technologies. This fast identification method for milk samples according to their thermal history possesses the potential for application in milk industry. In this context, the QCL-IR method could be a useful at-line tool for quality control and process analytical applications.

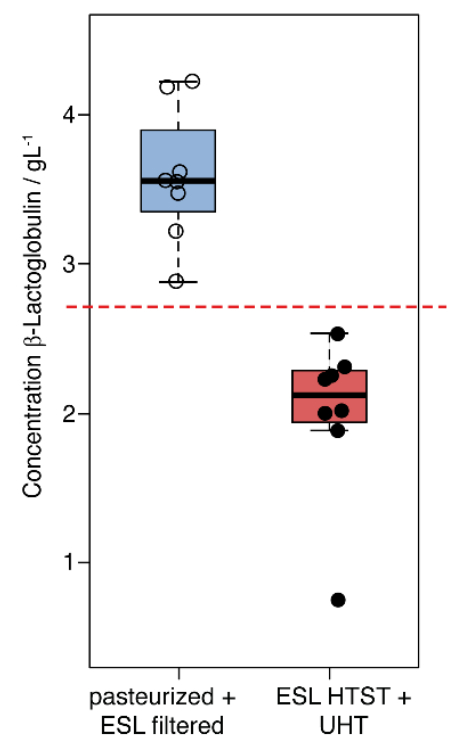

Fig. 3. Boxplots of commercial bovine milk samples after pasteurization procedures involving low (left/blue) and high (right/red) heat load. The red dashed line indicates the threshold of $2.7 \mathrm{~g} \mathrm{~L}^{-1} \beta$-LG obtained as computed by the ROC curve.

\section{Conclusion}

This manuscript reports a fast screening technique for the simultaneous determination of Cas, $\beta$ LG and total protein content of bovine milk samples employing an EC-QCL setup and chemometric modelling. The approach relies on the use of an external calibration data set based on mixtures of synthetic protein standards. Results of different types of commercially available milk samples subjected to diverse pasteurization and filtration techniques were carefully assessed and compared to 
those obtained by official and standardized reference methods. This very fast screening approach allows determining all three parameters within minutes, providing a substantial improvement in comparison to the reference methods, which involve several manual sample processing steps and the use of chromatographic analysis methods. Furthermore, this approach is potentially applicable for the assessment of the heat treatment of milk by means of measuring the concentration of $\beta-L G$ which is a parameter of interest for the milk industry.

\section{Acknowledgements}

Financial support was provided by the Austrian research funding association (FFG) under the scope of the COMET program within the research project "Industrial Methods for Process Analytical Chemistry - From Measurement Technologies to Information Systems (imPACts)" (contract \#843546). JK is grateful for her personal Miguel Servet grant (grant number: CP16/00034) provided by the Instituto Carlos III (Ministry of Economy and Competitiveness, Spain).

\section{Conflict of interest statement}

The authors declare no competing financial interests.

\section{References}

Aernouts, B., Polshin, E., Saeys, W., \& Lammertyn, J. (2011). Mid-infrared spectrometry of milk for dairy metabolomics: A comparison of two sampling techniques and effect of homogenization. Analytica Chimica Acta, 705(1-2), 88-97.

Alcaráz, M. R., Schwaighofer, A., Goicoechea, H., \& Lendl, B. (2016). EC-QCL mid-IR transmission spectroscopy for monitoring dynamic changes of protein secondary structure in aqueous solution on the example of beta-aggregation in alcohol-denaturated alpha-chymotrypsin. Analytical and Bioanalytical Chemistry, 408(15), 3933-3941.

Alcaráz, M. R., Schwaighofer, A., Kristament, C., Ramer, G., Brandstetter, M., Goicoechea, H., \& Lendl, B. (2015). External cavity-quantum cascade laser spectroscopy for mid-IR transmission measurements of proteins in aqueous solution. Analytical Chemistry, 87(13), 6980-6987.

Barth, A. (2007). Infrared spectroscopy of proteins. Biochimica et Biophysica Acta, Bioenergetics, 1767, 1073-1101.

Bhattacharjee, C., Saha, S., Biswas, A., Kundu, M., Ghosh, L., \& Das, K. P. (2005). Structural Changes of $\beta$-Lactoglobulin during Thermal Unfolding and Refolding - An FT-IR and Circular Dichroism Study. The Protein Journal, 24(1), 27-35.

Boitz, L. I., Fiechter, G., Seifried, R. K., \& Mayer, H. K. (2015). A novel ultra-high performance liquid chromatography method for the rapid determination of $\beta$-lactoglobulin as heat load indicator in commercial milk samples. Journal of Chromatography A, 1386, 98-102.

Boitz, L. I., \& Mayer, H. K. (2017). Extended shelf life milk - One concept, different qualities: A comprehensive study on the heat load of differently processed liquid milk retailed in Austria in 2012 and 2015. Lwt-Food Science and Technology, 79, 384-393.

Bordin, G., Cordeiro Raposo, F., de la Calle, B., \& Rodriguez, A. R. (2001). Identification and quantification of major bovine milk proteins by liquid chromatography. Journal of Chromatography A, 928(1), 63-76.

Claeys, W. L., Smout, C., Van Loey, A. M., \& Hendrickx, M. E. (2004). From time temperature integrator kinetics to time temperature integrator tolerance levels: Heat-treated milk. Biotechnology Progress, 20(1), 1-12. 
Etzion, Y., Linker, R., Cogan, U., \& Shmulevich, I. (2004). Determination of protein concentration in raw milk by mid-infrared Fourier transform infrared/attenuated total reflectance spectroscopy. Journal of Dairy Science, 87(9), 2779-2788.

Farrell, H. M., Wickham, E. D., Unruh, J. J., Qi, P. X., \& Hoagland, P. D. (2001). Secondary structural studies of bovine caseins: temperature dependence of beta-casein structure as analyzed by circular dichroism and FTIR spectroscopy and correlation with micellization. Food Hydrocolloids, 15(4-6), 341-354.

Fox, P. F., Uniacke-Lowe, T., McSweeney, P. L. H., \& O’Mahony, J. A. (2015). Milk Proteins. In Dairy Chemistry and Biochemistry, (pp. 145-239). Cham: Springer International Publishing.

Gondim, C. D., Junqueira, R. G., de Souza, S. V. C., Ruisanchez, I., \& Callao, M. P. (2017). Detection of several common adulterants in raw milk by MID-infrared spectroscopy and one-class and multi-class multivariate strategies. Food Chemistry, 230, 68-75.

Haug, A., Høstmark, A. T., \& Harstad, O. M. (2007). Bovine milk in human nutrition - a review. Lipids in Health and Disease, 6(1), 1-16.

Hougaard, A. B., Vestergaard, J. S., Varming, C., Bredie, W. L. P., \& Ipsen, R. H. (2011). Composition of volatile compounds in bovine milk heat treated by instant infusion pasteurisation and their correlation to sensory analysis. International Journal of Dairy Technology, 64(1), 34-44.

IDF/ISO. (2001a) Milk - Determination of nitrogen content - Part 1: Kjeldahl method. Standard 20-1. B. I. D. F. Brussels

IDF/ISO. (2001b) Milk - Determination of nitrogen content - Part 4: Determination of non-proteinnitrogen content. Standard IDF 20-4. B. I. D. F. Brussels

IDF/ISO. (2004) Milk-Determination of casein-nitrogen content - Part 1: Indirect method (reference method). Standard IDF 29-1. B. I. D. F. Brussels

IDF/ISO. (2005) Liquid milk - Determination of acid-soluble $\beta$-lactoglobulin content-Reversephased HPLC method. Standard 178. B. I. D. F. Brussels

Jaiswal, P., Jha, S. N., Kaur, J., \& Borah, A. (2017). Detection and quantification of anionic detergent (lissapol) in milk using attenuated total reflectance-Fourier Transform Infrared spectroscopy. Food Chemistry, 221, 815-821.

Justino, C. I. L., Rocha-Santos, T. A., \& Duarte, A. C. (2010). Review of analytical figures of merit of sensors and biosensors in clinical applications. TrAC-Trends in Analytical Chemistry, 29(10), 1172-1183.

Kaylegian, K. E., Lynch, J. M., Houghton, G. E., Fleming, J. R., \& Barbano, D. M. (2006). Modified versus producer milk calibration: Mid-infrared analyzer performance validation. Journal of Dairy Science, 89(8), 2833-2845.

Kuligowski, J., Schwaighofer, A., Alcaráz, M. R., Quintás, G., Mayer, H., Vento, M., \& Lendl, B. (2017). External Cavity-Quantum Cascade Laser (EC-QCL) Spectroscopy for Protein Analysis in Bovine Milk. Analytica Chimica Acta, 963, 99-105.

Luinge, H. J., Hop, E., Lutz, E. T. G., Vanhemert, J. A., \& Dejong, E. A. M. (1993). Determination of the Fat, Protein and Lactose Content of Milk Using Fourier-Transform Infrared Spectrometry. Analytica Chimica Acta, 284(2), 419-433.

Marbach, R. (2010). Multivariate calibration, selectivity, and the SBC method. Chemie Ingenieur Technik, 82(4), 453-466.

Mayer, H. K., Raba, B., Meier, J., \& Schmid, A. (2009). Extended shelf life (ESL) milk - milk with excessive heat load? European Dairy Magazine, (No.7), 18-22. 
Mayer, H. K., Raba, B., Meier, J., \& Schmid, A. (2010). RP-HPLC analysis of furosine and acidsoluble beta-lactoglobulin to assess the heat load of extended shelf life milk samples in Austria. Dairy Science \& Technology, 90(4), 413-428.

Mazurek, S., Szostak, R., Czaja, T., \& Zachwieja, A. (2015). Analysis of milk by FT-Raman spectroscopy. Talanta, 138, 285-289.

Moore, J. C., DeVries, J. W., Lipp, M., Griffiths, J. C., \& Abernethy, D. R. (2010). Total Protein Methods and Their Potential Utility to Reduce the Risk of Food Protein Adulteration. Comprehensive Reviews in Food Science and Food Safety, 9(4), 330-357.

O'Mahony, J. A., \& Fox, P. F. (2014). Milk: An Overview. In H. Singh, M. Boland \& A. Thompson (Eds.), Milk Proteins: From Expression to Food, 2nd Edition, (pp. 19-73).

Ribadeau-Dumas, B., \& Grappin, R. (1989). Milk protein analysis. Lait, 69(5), 357-416.

Rozenberg, S., Body, J. J., Bruyere, O., Bergmann, P., Brandi, M., Cooper, C., Devogelaer, J. P., Gielen, E., Goemaere, S., Kaufman, J. M., Rizzoli, R., \& Reginster, J. Y. (2016). Effects of Dairy Products Consumption on Health: Benefits and Beliefs-A Commentary from the Belgian Bone Club and the European Society for Clinical and Economic Aspects of Osteoporosis, Osteoarthritis and Musculoskeletal Diseases. Calcified Tissue International, 98(1), 1-17.

Rysstad, G., \& Kolstad, J. (2006). Extended shelf life milk - advances in technology. International Journal of Dairy Technology, 59(2), 85-96.

Schmidt, V. S. J., Kaufmann, V., Kulozik, U., Scherer, S., \& Wenning, M. (2012). Microbial biodiversity, quality and shelf life of microfiltered and pasteurized extended shelf life (ESL) milk from Germany, Austria and Switzerland. International Journal of Food Microbiology, 154(1-2), 1-9.

Schwaighofer, A., Alcaraz, M. R., Araman, C., Goicoechea, H., \& Lendl, B. (2016). External cavityquantum cascade laser infrared spectroscopy for secondary structure analysis of proteins at low concentrations. Scientific Reports, 6, 33556.

Schwaighofer, A., Brandstetter, M., \& Lendl, B. (2017). Quantum cascade lasers (QCLs) in biomedical spectroscopy. Chemical Society Reviews, 46, 5903-5924.

Simonet, B. M., Lendl, B., \& Valcarcel, M. (2006). Method-defined parameters: measurands sometimes forgotten. TrAC-Trends in Analytical Chemistry, 25(5), 520-527.

Strange, E. D., Malin, E. L., Van Hekken, D. L., \& Basch, J. J. (1992). Chromatographic and electrophoretic methods used for analysis of milk proteins. Journal of Chromatography A, 624(1), 81-102.

Wijayanti, H. B., Bansal, N., \& Deeth, H. C. (2014). Stability of Whey Proteins during Thermal Processing: A Review. Comprehensive Reviews in Food Science and Food Safety, 13(6), 1235-1251.

Xia, J., Sinelnikov, I. V., Han, B., \& Wishart, D. S. (2015). MetaboAnalyst 3.0—making metabolomics more meaningful. Nucleic Acids Research, 43(W1), W251-W257. 